\title{
Prevalence and intensity of Schistosoma mansoni and hookworm infections among pre-school and school-aged children in Ilemela District, north- western Tanzania
}

\author{
SAMUEL NDOKEJ ${ }^{*}$, HUMPHREY D. MAZIGO², MANSUET TEMU ${ }^{1}$, COLEMAN KISHAMAWE ${ }^{1}$, WABYAHE \\ MALENGANISHO ${ }^{1}$, JIM TODD ${ }^{3}$ and JOHN CHANGALUCHA ${ }^{1}$ \\ ${ }^{1}$ National Institute for Medical Research, Mwanza Research Centre, PO Box 1462, Mwanza, Tanzania \\ ${ }^{2}$ Catholic University of Health and Allied Sciences-Bugando, Mwanza, Tanzania \\ ${ }^{3}$ London School of hygiene \& Tropical Medicine, London, United Kingdom
}

\begin{abstract}
Introduction: World Health Organization have recently recommended the inclusion of pre-school children in the Mass Drug Administration (MDA) against schistosomiasis and soil-transmitted helminths in endemic areas. This study was conducted to determine the prevalence and intensity of Schistosoma mansoni and hookworm infections among pre- and school going children in Ilemela District, north-western Tanzania.

Methods: This cross-sectional study included pre- and school going children aged 4-14 years. A single stool sample was collected from each child and processed using Kato Katz thick smears and examined microscopically for presence of S. mansoni and hookworm eggs. A questionnaire was used to collect demographic information of the study participants.

Results: Overall, prevalence of S. mansoni was $80.0 \%$; with pre-school children aged $4-6$ years having the point prevalence of $60.6 \%$. The overall prevalence of hookworm infection was $18.7 \%$; with age group $4-6$ years having the prevalence of $14.1 \%$. The intensity of hookworm infection was light in all age groups. The intensity of infection of S. mansoni increased with age. Using lake water for domestic purposes $(\mathrm{OR}=3.09$, 95\% Cl: 1.93-4.95, $\mathrm{p}<0.001)$, for bathing ( $\mathrm{OR}=2.65,95 \% \mathrm{Cl}: 1.66-4.23, \mathrm{p}<0.0001)$, and for washing purposes $(\mathrm{OR}=3.08,95 \% \mathrm{Cl}: 1.90-4.97, \mathrm{p}<0.0001)$ remained independently associated with $\mathrm{S}$. mansoni infection. Children who reported to swim in the lake and involved in paddy farming had 1.84 and 1.95 times odds of being infected than those who did not, respectively.

Conclusion: These findings indicate that S. mansoni and hookworm infections are common among preschool children as well as in school going children. These findings call for the need to urgently include the pre-school age children in the MDA programme.
\end{abstract}

Keywords: Pre-school children, prevalence, Schistosoma mansoni, hookworm, Tanzania

\section{Introduction}

Schistosomiasis and soil transmitted helminths infections (STH) are among the neglected tropical diseases which are widely distributed in the worldwide. The former is estimated to infect over 230 million people and the later 3.5 billion people (Seto et al., 2012; Pullan et al., 2014). The subSaharan Africa region carries the highest burden of these infections, mainly because of poor sanitation and personal hygiene are low (Mascarini-Serra et al., 2010). Overall, Tanzania is the second highest country in Africa for the number of people infected with schistosomiasis. It is estimated that $52 \%$ of the population in Tanzania is infected or at risk of being infected with schistosomiasis (Mazigo et al., 2012). The prevalence and intensity of schistosomiasis in the country varies from one epidemiological setting to another.

Studies in Tanzania indicate that, the north-western regions which border the southern shores of the Lake Victoria carry the highest burden of schistosomiasis (Mazigo et al., 2012; Mugono et al., 2014; Bukindu et al., 2016). Similarly, STH especially hookworms remain as an important public health problem in north-western Tanzania, with prevalence ranging from $2 \%$ 40\% among schoolchildren (Mazigo et al., 2010; Mugono et al., 2015).

The main strategy for controlling these infection is through Mass Drug Administration (MDA), which mainly focuses in distributing anthelminthics to school children (WHO, 2002).

\footnotetext{
* Correspondence E-mail: samueldoto@yahoo.co.uk
} 
School MDA program is considered a cost effective means of reaching the majority of the school children in endemic areas who always carry the highest prevalence and intensity of infection (WHO., 2002). However, of recent, the approach has been criticised of leaving out pre- and nonschool going children, especially children aged 2-6 years who have been reported to be infected with schistosomiasis and STH (Ruganuza et al., 2015). In fact, pre-school accounts for $10-20 \%$ of the total population infected with STH worldwide (Albanico et al., 2008). Based on the evidence that pre-school age group is also infected, the World Health Organization has recommended the inclusion of the age group in the MDA programme (Ruganuza et al., 2015). However, there are limited data on the prevalence and intensity of schistosomiasis and STH among the pre-school children in most endemic areas of Tanzania. The present study was therefore conducted to determine the prevalence and intensity of S. mansoni and soil transmitted helminths infections among pre-school and school going children in Ilemela District of north-western Tanzania.

\section{Materials and methods}

\section{Study area and study population}

The study was conducted at Kayenze and Sangabuye villages in llemela district located between $32^{\circ} \mathrm{E}$ and $34^{\circ} \mathrm{E}$ and $2^{\circ} \mathrm{S}$ and $4^{\circ} \mathrm{S}$ on the southern shore of the Lake Victoria in north-western Tanzania. The region experiences temperature ranges from $25.7^{\circ} \mathrm{C}$ to $30.7^{\circ} \mathrm{C}$ and $1,000 \mathrm{~mm}$ of rainfall per year. Two schools of Sangabuye ward were purposely selected based on the fact that they are close to the shores of Lake Victoria and that had not been included in the schistosomiasis control programme. The majority of the inhabitants depend on the lake for domestic and economic activities including fishing, farming, washing, bathing, cooking, drinking and recreation. For preschool children some tend to play along the shores while others accompany their parents when cleaning their utensils and washing clothes, this increases the risk of being infected with S. mansoni or hookworm. According to the Tanzania national census, the population of Ilemela district in 2012 was 343,001 (NBS, 2013).

\section{Study design and sampling}

This was a cross sectional study conducted among pre-school attending village nursery schools and school aged children from local primary schools. Children were included in the study if (i) they were aged between 4-14 years; (ii) parents/guardians gave written informed consent; (iii) they gave an assent to participate; and (iv) they had no history of using anti-helminthic in the past 3-6 months. A total sample size of 350 children was required to obtain $95 \%$ confidence intervals of the prevalence of schistosomiasis and hookworm with a precision of $5 \%$. To compensate for drop outs and incomplete/missing values as a result of non-respondents and uncompleted questionnaires, the final sample was increased by $30 \%$ to 454 . Selection of the school children, and pre-school children, to participate in the study was achieved through the use of random sampling methods. From the attendance register, each child was given a unique identification number and a table of random number was used to selected study participants.

\section{Data collection}

A questionnaire based on the known risk factors for soil transmitted helminths and intestinal schistosomiasis was developed. Demographic information including sex, age, residence, school and village where the participants lived was recorded. Children were also asked if they participate in any of the economic activities such as in paddy farming or fishing. A single stool specimen was collected from each study participant for two consecutive days. From the stool samples collected on different days, two Kato Katz thick smears were prepared using a template of $41.7 \mathrm{mg}$ at the school environment and examined for hookworm eggs within 30-60 minutes after slides preparation (Barda et al., 2015; Siqueira et al., 2011). After 24 hours, the smears were independently examined by two laboratory technicians experienced with Kato Katz technique at 
the National Institute for Medical Research in Mwanza for presence of characteristics eggs of S. mansoni. For quality assurance, a random sample of $10 \%$ of the negative and positive of Kato Katz thick smears were re-examined by a third laboratory technician. Quality control for the hookworm eggs was carried out on $10 \%$ of the samples on the day of sample collection.

\section{Data analysis}

The quantitative data were double entered and managed in Census and survey processing system (CSPro) Version 4.1 and analysed using STATA 10 (StataCorp LP). The mean number of eggs for each infected child was computed by counting the total number of eggs multiplied by a factor of 24 to estimate infection intensities expressed as the number of eggs per gram of faeces (epg). The S. mansoni infection intensity was classified as light, moderate, or heavy where the egg count was in the range of 1-100 epg, 101-400 epg or >400 epg respectively (WHO, 2013). For STH the infection intensity was classified as light when the count was <1000 epg, moderate at 1000-3999 epg and heavy for $>4000$ epg (Knopp et al., 2008; Sayasone et al., 2015). Logistic regression was used to explore risk factors of S. mansoni and STH infections. Both crude odds ratios (OR) and $95 \%$ confidence intervals $(\mathrm{Cl})$, and then adjusting for age, sex and village were determined.

\section{Ethical consideration}

The study received ethical approval from the Medical Research Coordinating Committee of the National Institute for Medical Research Before carrying out the study, the study team visited the villages where leaders of the communities were met. The study objectives, procedures and benefits were explained to the care takers/parents of children before making request for their informed consent to have their children included in the study. Signed or thumbprint informed consent of parent/care takers were obtained. All study subjects were given standard treatment for hookworms and schistosomiasis according to the national guidelines.

\section{Results}

\section{Socio-demographic characteristics}

A total of 454 children were enrolled (males 215 and 239 females) into the study. The mean age was 9 years. Study participants were divided into three groups: pre-school children (4-6 years), early primary schoolchildren (7-10 years) and late primary schoolchildren (11-14 years) (Table 1).

Table 1: Age prevalence of hookworm and Schistosoma mansoni infection of children

\begin{tabular}{|c|c|c|c|c|c|c|c|c|c|}
\hline \multirow[t]{2}{*}{ Variable } & & \multicolumn{4}{|l|}{ Hookworm } & \multicolumn{4}{|l|}{ S. mansoni } \\
\hline & & $\begin{array}{l}\text { Kayenze } \\
\mathrm{n}(\%)\end{array}$ & $\begin{array}{l}\text { Sangabuye } \\
\mathrm{n}(\%)\end{array}$ & All n (\%) & $p$-value & $\begin{array}{l}\text { Kayenze } \\
\mathrm{n}(\%)\end{array}$ & $\begin{array}{l}\text { Sangabuye } \\
\mathrm{n}(\%)\end{array}$ & All n (\%) & p-value \\
\hline \multirow{3}{*}{$\begin{array}{l}\text { Age } \\
\text { (years) }\end{array}$} & $4-6$ & $0(0.0)$ & $10(27.0)$ & $10(14.1)$ & 0.37 & $31(91.2)$ & $12(32.4)$ & $43(60.6)$ & $<0.0001$ \\
\hline & $7-10$ & $17(12.0)$ & $38(24.1)$ & $55(18.3)$ & & $139(97.9)$ & $107(67.7)$ & $246(82.0)$ & \\
\hline & $11-14$ & $13(31.0)$ & $7(17.1)$ & $20(24.1)$ & & $42(100.0)$ & $32(78.1)$ & $74(89.2)$ & \\
\hline \multirow[t]{2}{*}{ Sex } & Male & $13(12.6)$ & $25(22.3)$ & $38(17.7)$ & 0.69 & $100(97.1)$ & $76(67.9)$ & $176(81.9)$ & 0.32 \\
\hline & Female & $17(14.8)$ & $30(24.2)$ & $47(19.7)$ & & $112(97.4)$ & $75(60.5)$ & $187(78.2)$ & \\
\hline Overall & & $30(13.8 \%)$ & $55(23.3 \%)$ & $85(18.7 \%)$ & & $212(97.2)$ & $151(64.0 \%)$ & $363(80.0)$ & \\
\hline
\end{tabular}

\section{Prevalence and intensity of S. mansoni and hookworm infection}

S. mansoni and hookworm were the only parasites detected by the Kato Katz technique. The overall prevalence of hookworm infection was $18.7 \%$ (85/454). The age group specific prevalence was $14.1 \%$ in $4-6$ years, $18.3 \%$ in $7-10$ years and $24.1 \%$ in $11-14$ years old children with no significance difference between age groups $(p$-value $=0.37)$ and sex $(p$-value $=0.69)$. The overall prevalence of S. mansoni was $80.0 \%$ (363/454). The age group specific prevalence of S. mansoni was $60.6 \%$ in the preschool children $4-6$ years, $82.0 \%$ in those aged $7-10$ years, and $89.2 \%$ in the age group of 11 - 
14 years. The difference in prevalence of S. mansoni observed between age group was statistically significant ( $p$-value $<0.0001$ ) (Table 1).

Table 2: Intensity of Schistosoma mansoni infection by age and sex

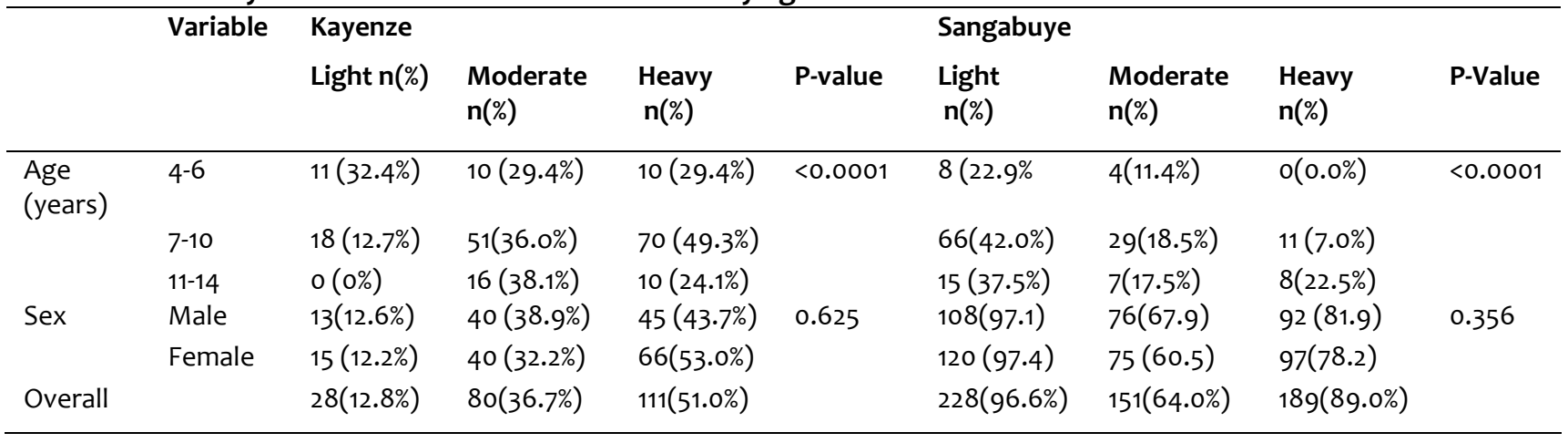

The intensity of hookworm infection both in Kayenze and Sangabuye was light in all age groups. There was a significant difference in intensity between the age groups ( $p$-value <0.0001). Sixtytwo percent of schoolchildren aged 11-14 years in Kayenze had heavy intensity of S. mansoni infection than those from Sangabuye village. There were no significant differences in the intensity of S. mansoni infection by sex between the two villages (Table 2).

Table 3: Association of Schistosoma mansoni infection with open water sources contact habits of children

\begin{tabular}{|c|c|c|c|c|c|}
\hline Risk factor & Response & $\begin{array}{l}\text { No. (\%) Positive } \\
\text { for S. mansoni }\end{array}$ & $\mathrm{X}^{2} \mathrm{P}$ value & $\begin{array}{l}\text { Crude } \\
\text { OR }\end{array}$ & $95 \% \mathrm{Cl}$ \\
\hline \multirow[t]{2}{*}{ Use lake water for domestic purpose } & Yes & $257(86.53)$ & & 3.09 & $1.93-4.95$ \\
\hline & No & $106(67.52)$ & $<0.001 *$ & 1.00 & \\
\hline \multirow[t]{2}{*}{ Use river water for domestic purpose } & Yes & $55(74.32)$ & & 0.68 & $0.38-1.21$ \\
\hline & No & $305(81.05)$ & 0.186 & 1.00 & \\
\hline \multirow{2}{*}{$\begin{array}{l}\text { Use damp water for domestic } \\
\text { purpose }\end{array}$} & Yes & $42(73.68)$ & & 0.66 & $0.35-1.26$ \\
\hline & No & $321(80.86)$ & 0.206 & 1.00 & \\
\hline \multirow[t]{2}{*}{ Use lake/pond water for bathing } & Yes & $252(85.71)$ & & 2.65 & $1.66-4.23$ \\
\hline & No & $111(69.38)$ & $0.0001 *$ & 1.00 & \\
\hline \multirow[t]{2}{*}{ Use lake water for washing } & Yes & $227(87.64)$ & & 3.08 & $1.90-4.97$ \\
\hline & No & $136(69.64)$ & $0.0001 *$ & 1.00 & \\
\hline \multirow[t]{2}{*}{ Use river water for washing } & Yes & $48(78.69)$ & & 0.91 & $0.471-1.77$ \\
\hline & No & $315(80.15)$ & 0.79 & 1.00 & \\
\hline \multirow[t]{2}{*}{ Use pond water for washing } & Yes & $30(75.0)$ & & 0.73 & $0.34-1.55$ \\
\hline & No & $333(80.43)$ & 0.412 & 1.00 & \\
\hline \multirow[t]{2}{*}{ Bathing in the lake } & Yes & $159(83.23)$ & & 1.44 & $0.89-2.32$ \\
\hline & No & $204(77.57)$ & 0.136 & 1.00 & \\
\hline \multirow[t]{2}{*}{ Fetching water in the lake } & Yes & $20(80.0)$ & & 1.00 & $0.37-2.75$ \\
\hline & No & $79(79 \cdot 95)$ & 0.995 & 1.00 & \\
\hline \multirow[t]{2}{*}{ Fording in transit } & Yes & $95(78.51)$ & & 0.89 & $0.53-1.48$ \\
\hline & No & $268(80.48)$ & 0.643 & 1.00 & \\
\hline \multirow[t]{2}{*}{ Swimming in the lake } & Yes & $144(85.71)$ & & 1.84 & $1.10-3.06$ \\
\hline & No & $219(76.57)$ & 0.019 & 1.00 & \\
\hline \multirow[t]{2}{*}{ Involved in paddy farming } & Yes & $83(87.37)$ & & 1.95 & $1.01-3.76$ \\
\hline & No & $280(77.99)$ & 0.042 & 1.00 & \\
\hline
\end{tabular}

* The difference was statistically significant $(P<0.05)$

\section{Risk factors for S. mansoni and STH infection}

Factors that were significantly associated with schistosomiasis infection in unadjusted analysis included, using lake water for domestic purposes (OR=3.09, 95\% Cl: 1.93-4.95, $\mathrm{p}<0.001)$, using lake 
water or pond for bathing ( $\mathrm{OR}=2.65,95 \% \mathrm{Cl}: 1.66-4.23, \mathrm{p}<0.0001)$, and using lake water for washing purposes (OR=3.08, 95\% Cl: 1.90-4.97, $\mathrm{p}<0.0001$. Children who reported to swim in the lake had 1.84 times higher odds of being infected than those who did not (OR=1.84, 95\% Cl: 1.10 3.06). Children who were frequently involved in paddy farming activities were 1.95 times more likely to have S. mansoni infection than those who did not (OR=1.95, $95 \% \mathrm{Cl}$ : 1.01-3.76) (Table 3). After adjusting for age, sex and village, using lake water for domestic purpose and frequent use of lake water for washing were not associated with S. mansoni infection (OR 1.32, 95\% Cl: 0.772.28, $\mathrm{P}=0.32$ and $\mathrm{OR} 1.48,95 \% \mathrm{Cl}: 0.86-2.57, \mathrm{P}=0.159$, respectively) (Table 4).

Table 4: Odds ratios for factors associated with S. mansoni adjusted for age, sex and village

\begin{tabular}{|c|c|c|c|c|c|c|}
\hline Risk factors & Response & $\begin{array}{l}\text { Positive for } \\
\text { S. mansoni } \\
n(\%)\end{array}$ & $\begin{array}{c}\mathrm{X}^{2} \\
\text { value }\end{array}$ & $\mathbf{P}$ & Adjusted OR & $95 \% \mathrm{Cl}$ \\
\hline \multirow{2}{*}{$\begin{array}{l}\text { Use lake water for domestic } \\
\text { purpose }\end{array}$} & Yes & $257(86.53)$ & & & 1.32 & $0.77-2.28$ \\
\hline & No & $106(67.52)$ & 0.315 & & 1.00 & \\
\hline \multirow{2}{*}{$\begin{array}{l}\text { Use lake water/Pond for } \\
\text { bathing }\end{array}$} & Yes & $252(85.71)$ & & & 1.50 & $0.88-2.57$ \\
\hline & No & $111(69 \cdot 38)$ & 0.135 & & 1.00 & \\
\hline \multirow{2}{*}{$\begin{array}{l}\text { Use lake water for washing } \\
\text { purpose }\end{array}$} & Yes & $227(87.64)$ & & & 1.48 & $0.86-2.57$ \\
\hline & No & $136(69.74)$ & 0.159 & & 1.00 & \\
\hline \multirow[t]{2}{*}{ Swimming in the lake } & Yes & $144(85.71)$ & & & 1.22 & $0.65-2.26$ \\
\hline & No & $219(76.57)$ & 0.658 & & 1.00 & \\
\hline \multirow[t]{2}{*}{ Paddy swimming } & Yes & $83(87.37)$ & & & 1.03 & $0.48-2.22$ \\
\hline & No & $280(77.99)$ & 0.942 & & 1.00 & \\
\hline
\end{tabular}

Table 5: Association of hookworm infection with soil contact habit of children aged 4-14 years

\begin{tabular}{|c|c|c|c|c|c|}
\hline Risk factor & Response & $\begin{array}{l}\text { No. (\%) Positive } \\
\text { for hookworm }\end{array}$ & $X^{2} P$ value & $\begin{array}{l}\text { Crude } \\
\text { OR }\end{array}$ & $95 \% \mathrm{Cl}$ \\
\hline \multirow[t]{2}{*}{ Shoe wearing behaviour } & Yes & $382(18.8)$ & & 1 & \\
\hline & No & $72(18.1)$ & 0.87 & 1.05 & $0.55-2.02$ \\
\hline \multirow[t]{2}{*}{ Washing hands after visiting latrines } & Yes & $56(18.06)$ & & 1 & \\
\hline & No & $29(20.14)$ & 0.598 & 1.07 & $0.83-1.37$ \\
\hline \multirow[t]{2}{*}{ Wash hands before eating } & Yes & $83(18.57)$ & & 1 & \\
\hline & No & $2(28.57)$ & 0.501 & 1.23 & $0.89-1.69$ \\
\hline \multirow[t]{2}{*}{ Soil eating habits } & Yes & $13(14.13)$ & & 1 & \\
\hline & No & $72(19.89)$ & 0.206 & 1.23 & $0.89-1.69$ \\
\hline \multirow[t]{3}{*}{ Washing fruits before eating } & Yes & $41(17.15)$ & & 1 & \\
\hline & No & $25(19.84)$ & 0.592 & 1.20 & $0.69-2.08$ \\
\hline & Sometimes & $18(21.95)$ & & 1.36 & $0.73-2.53$ \\
\hline
\end{tabular}

There was no significant difference in hookworm infection among children who reported wearing shoes and those who did not or between those who reported washing their hands after visiting the toilet or washing hands before eating than those who did not (Table 5). On stratifying the children by school age and pre-school age there were no significant differences by shoe wearing or washing hands after visiting the toilets.

\section{Discussion}

The region of north-western Tanzania has been reported by several previous studies to be highly endemic to schistosomiasis and soil-transmitted helminths (Lwambo et al., 1999; Kinung'hi et al., 2014; Mazigo et al., 2010; Mugono et al., 2015). For the soil-transmitted helminths, hookworms 
appear to be a predominant species among children along the shore line of Lake Victoria (Lwambo et al., 1999: Mazigo et al., 2010). Similarly, the findings from this study demonstrate that S. mansoni and hookworm infections remain as significant public health problems among preschool and school aged children in the study area.

Our findings on the high prevalence of S. mansoni infection among pre-school aged children in this region are corroborated with the finding of a recent study in the same age group by Ruganuza et al. (2015). Similar studies elsewhere in Sub-Saharan Africa have demonstrated that the pre-school aged group remains at high risk of developing significant hepatosplenic morbidities with increased age (Stothard \& Gabrielli, 2007; Anon, 2010; Stothard et al., 2011; Hodges et al., 2012; Coulibaly et al., 2013). This is due to the fact that the age group is infected at young age and carry the infection for long periods before it is included in the MDA programmes. Unsparingly, this study complements the findings from other studies, indicating that the prevalence of S. mansoni and hookworm tends to increase across age groups. The explanation to this is the cumulative exposure to infection as water contact of the children increases with age. Like in this study, several other studies have already shown that the prevalence of S. mansoni infection is high in school aged than the pre-school children (Pereira et al., 2010; Mazigo et al., 2010; Mugono et al., 2015).

The sex distribution of S. mansoni in this study did not show any significant variation. This indicates that children at this age group have the similar exposure to risk of being infected with $\mathrm{S}$. mansoni. The findings are similar to those reported from northwest Ethiopia by Worku et al., 2014. However, other studies have reported higher prevalence of S. mansoni infection among boys than girls (Mazigo et al., 2010), most likely attributed to varied social-gender related reasons.

Three classes of intensity of S. mansoni infection in pre-school children (light, moderate and heavy) were observed in Kayenze; while for Sangabuye the most significant were the light and moderate intensities. The differences in intensities between the two villages are explained by the fact that Kayenze is closer to the lake $(350 \mathrm{~m})$ than Sangabuye $(1,500 \mathrm{~m})$. The close proximity of the lake to Kayenze defines the high frequency of visiting the lake for various domestic tasks. Our findings are consistent with the observations reported by Ruganuza et al. (2015) that going to the lake or living close to the lake are associated with risks of being infected with S. mansoni. The intensity of infection in pre-school children is lower than that of school age children because parental care is higher in this age group than in the school aged children, who are old enough to freely move about the lake shores alone.

In conclusion, the findings of this study indicate that the prevalence of intestinal schistosomiasis among pre-school and school-aged children in villages around Lake Victoria in Tanzania is high. This calls for the implementation of a coherent control strategy. There is a need for the National Schistosomiasis and Intestinal Worm Control Programme to include pre-school children in the interventions. A community sensitization programme to promote the provision of safe and adequate water supply, latrine construction and use to reduce open field defecation and health education is critical.

\section{Acknowledgements}

The authors wish to thank Ministry of Health and Social welfare (Tanzania) for financial support. We appreciate the support provided by Ilemela District Medical and Education Officers. We would also like to thank village leaders, teachers, parents and children of all villages and schools for their enthusiasm and participation in the study. We are grateful to the Director, Mwanza Medical Research Centre for logistical support. Special thanks to Dr. Tibuhinda Ngonzi of St. Augustine University of Tanzania for his comments on the earlier version of the manuscript. 


\section{Author contributions}

SN conceived the study and developed the proposal; CK carried out the statistical analysis; and JT contributed to the analysis and interpretation of the data. All authors contributed to the design and data analysis, read and approved the final version of the manuscript.

\section{Competing interests}

None declared.

\section{References}

Barda, B., Albonico, M., Ianniello, D., Ame, S.M., Keiser, J., Speich, B., Rinaldi, L., Cringoli, G., Burioni, R., Montresor, A. \& Utzinger, J. (2015) How long can stool samples be fixed for an accurate diagnosis of soil-transmitted helminth infection using Mini-FLOTAC? PLoS Neglected Tropical Diseases 9(4): e0003698.

Coulibaly, J.T., N'Gbesso, Y.K., N'Guessan, N.A., Winkler, M.S., Utzinger, J. \& N'Goran, E.K. (2013) Epidemiology of schistosomiasis in two high-risk communities of south Cote d'lvoire with particular emphasis on pre-school-aged children. American Journal of Tropical Medicine and Hygiene 89, 32-41.

Hodges, M.H., Paye, J., Koroma, M.M., Nyorkor, E.D., Fofonah, I. \& Zhang, Y. (2012) High level of Schistosoma mansoni infection in pre-school children in Sierra Leone highlights the need in targeting this age group for praziquantel treatment. Acta Tropica 124, 120-125.

Kinung'hi, S.M., Magnussen, P., Kaatano, G.M., Kishamawe, C. \& Venervald, B.J. (2014) Malaria and helminth co-infections in school and pre-school children: a cross sectional study in Magu district, north-western Tanzania. PLoS One Neglected Tropical Diseases 9(1): e 86510.

Knopp, S., Mgeni, A.F., Khamis, I.S., Steinmann, P., Stothard, J.R., Rollinson, D., Marti, H. \& Utzinger, J. (2008) Diagnosis of soil-transmitted helminths in the era of preventive chemotherapy: effect of multiple stool sampling and use of different diagnostic techniques. PLoS Neglected Tropical Diseases 2(11): e331.

Mascarini-Serra, L.M., Telles, C.A., Prado, M.S., Mattos, S.A., Strina, A., Alcantara-Neves, N.M. \& Barreto, M.L. (2010) Reductions in the prevalence and incidence of geohelminth infection following a city-wide sanitation program in a Brazilian Urban Centre. PloS Neglected Tropical Diseases 4(2): e588.

Mazigo, H.D., Waihenya, R., Lwambo, J.S., Mnyone, L., Mahande, M. \& Mkoji, M.G. (2010) Coinfections with Plasimodium falciparum, Schistosoma mansoni and intestinal helminths among school children in endemic areas of northwestern Tanzania. Parasites and Vectors 3:44.

Mazigo, H.D., Nuwaha, F., Kinung'hi, S.M., Morona, D., de Moira, A., Wilson, S., Heukelbach, J. \& Dunne, D.W. (2012) Epidemiology and control of human schistosomiasis in Tanzania. Parasites \& Vectors 5 (1): 274

NBS (2013) 2012 Population and Housing Census. National Bureau of Statistics, United Republic of Tanzania.

Pereira, A.P., Favre, T.C., Galvão, A.F., Beck, L., Barbosa, C.S. \& Pieri, O.S. (2010) The prevalence of schistosomiasis in school-aged children as an appropriate indicator of its prevalence inthe community. Memorias do Instituto Oswaldo Cruz 105, 563-569.

Pullan, R.L., Smith, J.L., Jasrasaria, R. \& Brooker, S.J. (2014) Global numbers of infection and disease burden of soil transmitted helminth infection sis 2010. Parasites \& Vectors 7:37

Ruganuza, D.M., Mazigo, H.D., Waihenya, R., Morona, D. \& Mkoji, G.M. (2015) Schistosoma mansoni among pre-school children in Musozi village, Ukerewe Island, north-western Tanzania: prevalence and associated risk factors. Parasites \& Vectors 8:377. 
Sayasone, S., Utzinger, J., Akkhavong, K. \& Odermatt, P. (2015) Multiparasitism and intensity of helminth infection in relation to symptoms and nutritional status among children: a crosssectional study in southern Lao People's Democratic Republic. Acta Tropica 141, 322-331.

Seto, E.Y., Sousa-Figueiredo, J.C., Betson, M., Byalero, C., Kabatereine, N.B. \& Stothard, J.R. (2012) Patterns of intestinal schistosomiasis among mothers and young children from Lake Albert, Uganda: water contact and social networks inferred from wearable global positioning system datalogger. Geospatial Health 7: 1-13.

Siqueira, L.M.V., Coelho, M.Z., de Oliveira, A.A., Massara, C.L., de Figueiredo Carneiro, N.F., Lima, A.C.L. \& Enk, M.J. (2011) Evaluation of two coproscopic techniques for the diagnosis of schistosomiasis in a low-transmission area in the state of Minas Gerais, Brazil. Memoris do Instituto Oswaldo Cruz 106, 844-850.

Sow, S., De Vlas, S.J., Stelma, F., Vereecken, K., Gryseels, B. \& Polman, K. (2011) The contribution of water contact behavior to the high Schistosoma mansoni infection rates observed in the Senegal River Basin. BMC infectious Diseases 11: 198

Steinmann, P., Keiser, J., Bos, R., Tanner, M. \& Utzinger J. (2006) Schistosomiasis and water resource development: systematic review, meta-analysis, and estimates of people at risk. Lancet Infectious Diseases 6(7): 411-425

Stothard, J.R. \& Gabrielli, A.F. (2007) Schistostomiasis in African infants and preschool children: to treat or not to treat? Trends in Parasitology 23, 83-86.

Stothard, J.R. (2011) Schistosoma mansoni infections in young children: when are schistosome antigens in urine, eggs in stool and antibodies to eggs first detecable? PloS Neglected Tropical Diseases 5(1): e938.

Stothard, J.R., Sousa-Figueiredo, J.C., Betson, M., Bustinduy, A. \& Reinhard-Rupp, J. (2013) Schistosomiasis in African infants and preschool children: let them now be treated! Trends in Parasitology 29, 197-205.

WHO (2013) Schistosomiasis Progress Report 2001-2011 and Strategic Plan 2012-2012. World Health Organization, Geneva, Switzerland.

Worku, L., Damte, D., Endris, M., Tesfa, H. \& Aemero, M. (2014) Schistosoma mansoni infection and associated determinant factors among school children in Sanja Town, northwest Ethiopia. Journal of Parasitology Research 2014 Article ID 792536. 